\title{
MASCULINIDADES NO ESPORTE: O CASO DO RUGBY
}

MASCULINITIES IN SPORT: THE CASE OF RUGBY

MASCULINIDADES EN EL DEPORTE: EL CASO DEL RUGBY

Francisca Islandia Cardoso da Silva*, Dulce Maria Filgueira de Almeida*

Palavras chave: Esportes. Identidade de gênero. Masculinidade.

\section{Keywords:}

Sports. Gender Identity. Masculinity.

\section{Palabras clave:} Deportes. Identidad de Género. Masculinidad.
Resumo: O ensaio objetiva problematizar o rugby como prática mediadora na configuração de significados de masculinidades. Em meio ao processo civilizatório e ao movimento sufragista, o regulamento da modalidade e as masculinidades defendidas pelos praticantes sofreram modificações. O rugby realizou um movimento não linear em que ora reproduz concepções tradicionais, ora contribui para tensionamentos nas relações de gênero.

Abstract: This essay debates rugby as a mediating practice when configurating meanings of masculinities. Amidst the civilizing process and the suffragist movement, rugby's rules and the masculinities advocated by its practitioners underwent changes. Rugby has traveled a non-linear path where it sometimes reproduces traditional conceptions and sometimes contributes to tensions in gender relations.

Resumen: El ensayo objetiva problematizar el rugby como práctica mediadora en la configuración de significados de masculinidades. En medio al proceso civilizatorio y al movimiento sufragista, el reglamento de la modalidad y las masculinidades defendidas por los practicantes sufrieron modificaciones. El rugby realizó un movimiento no lineal en el que a veces reproduce concepciones tradicionales, a veces contribuye a tensiones en las relaciones de género.
*Universidade de Brasília. Brasília, DF, Brasil.

E-mail:

islandiacardoso@hotmail.com; dulce.filgueira@gmail.com

Recebido em: 02-07-2019 Aprovado em: 16-04-2020 Publicado em: 08-06-2020

(c) (i) (2) Licence 


\section{INTRODUÇÃO}

Segundo Bracht (2005), o esporte moderno consiste em atividade de caráter competitivo, surgida na Europa por volta do século XVIII, resultante do processo de modificação de elementos da cultura corporal de movimento. O autor pontua que a crítica do esporte é, também, a crítica da sociedade, reconhecendo que aquele é, preservando-se suas especificidades, um exemplo de prática social, logo, passível de modificações.

No imaginário social, o rubgy é considerado um esporte eminentemente "masculino". Essa ideia faz com que esta modalidade seja - por vezes, mecanicamente - associada à produção de uma determinada configuração de masculinidade, em razão de um conjunto de procedimentos técnicos e táticos que a envolvem, bem como em decorrência do processo histórico de sua constituição como um fenômeno secular moderno.

A partir da aparência dos corpos, os sujeitos são classificados, hierarquizados e definidos por meio da incorporação de marcas de poder que atendam aos padrões e referências culturais contextuais (LOURO, 2004). O corpo é afetado por processos e agentes sociais, como os costumes, o mercado de trabalho, a urbanização, a educação e o esporte. Essas influências são estruturadas pelo gênero, logo, arranjos de gênero não são mero efeito de propriedades anatômicas do corpo; eles "[...] também precedem o corpo, formando as condições em que este se desenvolve e vive" (CONNELL; PEARSE, 2015, p. 93).

No caso do rugby, os comportamentos esperados em relação ao gênero masculino são significados e reforçados de diferentes formas, forjando-se uma espécie de manual do bom comportamento, em que são prescritas normas de condutas a serem seguidas pelos praticantes deste esporte. Contudo, essas normas de conduta que reforçam padrões e estereótipos no rugby precisam ser melhor evidenciadas e compreendidas, visto que, como qualquer outra forma de disciplinamento, constituise por um mecanismo de controle sobre o corpo.-

Este ensaio objetiva, a partir de uma abordagem socio-histórica, problematizar a potencial mediação do rugby no processo de configuração de masculinidades. Para tanto, a trajetória escolhida foi tratar o rugby como esporte moderno, à luz dos escritos de Norbert Elias e Eric Dunning; ao tempo em que se evidencia uma clara relação entre este esporte, a constituição de masculinidades e a conformação de um habitus próprio, que se dá com a passagem de um esporte de elite para um esporte da classe trabalhadora inglesa. Ademais, discute-se, com fundamento em Raewyn Connell, a questão de gênero e o universo masculino. Organiza-se o texto por meio da contextualização acerca das normas do rugby (código) e, por conseguinte, tratase das ambivalências entre o amadorismo e a profissionalização neste esporte, que se apresenta como um mediador peculiar de masculinidade, ou seja, um ethos guerreiro, ferramenta de controle dos corpos. 


\section{OS PRIMEIROS ESCRITOS DO CÓDIGO DO RUGBY}

A partir do século XVI, na Europa Ocidental, os modelos sociais de conduta, particularmente nas classes sociais altas começam a se transformar na direção do banimento de excessos de autopunição e autocomplacência. A mudança encontrou expressão no conceito de civilidade, "[...] símbolo de um novo refinamento das maneiras" (ELIAS, 1985a, p. 41). Também o desenvolvimento do esporte e, em particular, do rugby, passou por mudanças em seus preceitos de conduta e sensibilidade à violência.

No século XVIII, além do prosseguimento do processo civilizatório, a sociedade inglesa assiste à insurgência de mulheres contra a desigualdade de gênero. Em meados do século XIX, torna-se notório que o movimento sufragista, mesmo não alcançando totalmente seus objetivos, causou um desequilíbrio nas relações entre homens e mulheres na Inglaterra. O incremento de alguns direitos às mulheres foi lido por parte dos homens como uma ameaça à sua posição de dominância, principalmente àqueles da classe social média, a que pertencia, também, a maioria das sufragistas. Em resposta, parte deles se mobilizou em torno do rugby como um enclave onde poderiam reforçar o modelo de masculinidade ameaçado e ratificar as mulheres como o sexo frágil. Percebe-se nas ações desses homens uma atitude hostil, e, paradoxalmente, medrosa em relação às mulheres - que passaram a desafiar as estruturas sociais -, e a qualquer ato considerado afeminado (DUNNING, 1985b).

Existem indícios de que o rugby é originário de uma variedade de jogos medievais praticados segundo regras orais, em campos abertos e ruas dos vilarejos através da Inglaterra (RIAL, 2000). Esses jogos expressavam uma forma extrema de regime patriarcal caracterizado por: estruturas de Estado e de desenvolvimento social de níveis relativamente reduzidos, atos de violência regularmente manifestos na vida cotidiana e, mecanismos de poder entre os gêneros, nitidamente, favoráveis aos homens. "Como tal, integravam a expressão macho de uma forma relativamente desabrida" (DUNNING, 1985b, p. 395).

No século XIX, na escola pública inglesa - com início na Rugby School-o rugby emerge, gradualmente, como um jogo com características distintivas (ALASALMI, 2014). A composição desse sistema educacional por jovens filhos da aristocracia e da classe média foram determinantes para a construção de uma identidade de nobreza, cavalheirismo e virilidade. Isso porque, o objetivo dessas instituições era a formação, em nível de excelência, de homens saudáveis e fortes chefes de empreendimento ou oficiais militares (BETTI, 2009). Significado como uma prática simbólica de confronto, o rugby foi exaltado como mecanismo ideal de educação e socialização dos futuros líderes militares e administrativos da nação britânica e veículo de imposição e expressão da virilidade (DUNNING, 1985b).

O esporte é espaço de observação, avaliação e comparação de seus praticantes, recebendo maior ganho distintivo - utilizando o termo de Bourdieu (2003) - aqueles que alcancem melhor desempenho e resultados efetivos. Nessa perspectiva, pressionados pela sociedade britânica a praticar esportes, os homens 
jovens se viam obrigados a se adaptar à regra; caso contrário, arriscavam-se a ser qualificados como afeminados, o que era associado à noção de homossexualidade. Praticar esportes competitivos, em que a dominação física é celebrada, representa importante recurso social de experiência e validação da masculinidade durante a juventude e a vida adulta, atuando como barreira contra a feminização e emasculação (CONNELL; PEARSE, 2015, DUNNING; MAGUIRE, 1997).

Em 1845, na Rugby School, formalizaram-se as primeiras regras do rugby, entre as quais "proibir, por completo, o uso das navvies" (botas com ponta de ferro valorizadas em jogo em Rugby e outras escolas), apontando para o declínio do culto à violência (DUNNING, 1985a, p. 336). Concebido pela filosofia aristocrática como escola de coragem e virilidade, "[...] capaz de 'formar o caráter' e inculcar a vontade de vencer", o esporte deveria respeitar regras e adotar o fair play, disposição oposta à busca da vitória a qualquer preço (BOURDIEU, 2003, p. 187). Apesar disso, o rugby não se tornou área livre dos "[...] preconceitos patriarcais, característicos de uma sociedade que se encontrava num estágio ainda relativamente inicial da sua emergência como um Estado-nação urbano e industrial” (DUNNING, 1985b, p. 395).

Para solucionar as críticas quanto à violência do rugby, criou-se a Football Association (FA), responsável por reger o rugby football e o futebol inglês. No entanto, no final de 1863, após a FA proibir o porte da bola pelas mãos e os chutes nas pernas dos adversários (as chamadas caneladas) - características centrais do rugby na época -, os clubes ingleses de rugby se recusaram a ingressar na federação. Os defensores das caneladas argumentaram que sua abolição "tornaria o jogo “afeminado'” (ELIAS; DUNNING, 1985, p. 288).

Os atributos ligados ao rugby compõem o que Elias (1985b, p. 204) chama "ethos guerreiro", que pode ser utilizado como uma ferramenta de controle dos corpos. No século XIX, a modalidade é assinalada pelo culto à violência e à força, pelo controle e disciplinamento do corpo quanto à dor, pela misoginia e homofobia. Por conseguinte, o processo civilizatório pelo qual passava o jogo era caracterizado por alguns praticantes como um processo de feminização do rugby, já que "enquanto o ideal masculino é retratado como arrogante" e forte (tanto física, quanto psicologicamente), "o ideal feminino - segundo a perspectiva masculina é representado como tímido, frágil e dependente" (DUNNING, 1985b, p. 398-399). Evitar a disputa física com o adversário era um ato covarde, afeminado; não condizia com o ethos guerreiro necessário a um homem jogador de rugby (RIAL, 2000).

Apesar de não fazer referência ao rugby, Pierre Bourdieu (2012), no livro "A dominação masculina", explica essa preocupação em cumprir um dado modelo de masculinidade no/do rugby. O autor afirma que a ordem masculina impõe ao homem a obrigação de possuir e demonstrar, a todo momento, virilidade, a qual caracterizaria sua capacidade reprodutiva, sexual e social.

Ser homem "[...] não é algo espontâneo, precisa ser constantemente atestado, ainda que tenha uma contrapartida generosa" (RIAL, 2000, p. 254). Porém, essa virilidade é, ao mesmo tempo, a glória e a angústia do homem, pois leva ao investimento "em todos os jogos de violência [...] e mais especialmente os que são mais adequados a produzir os signos visíveis da masculinidade e para manifestar, 
bem como testar, as qualidades ditas viris" (BOURDIEU, 2012, p. 65). Uma das formas de demonstrar esse atributo e estabelecer a reputação masculina é por meio das práticas corporais, principalmente quando arriscadas, como o é o rugby.

No final do século XIX, a controvérsia pública sobre a canelada continuou. O nível de violência se tornou uma ameaça à aceitação do rugby como um esporte civilizado. Por esta razão, a Rugby Football Union (RFU), estabelecida em $1871 \mathrm{com}$ o objetivo de unificar as regras do jogo, decidiu abolir a prática dos chutes nas pernas (DUNNING, 1985a), apesar das críticas daqueles para quem um jogo de rugby não seria completo sem uma oportunidade real de mostrar sua bravura - em outras palavras, dando e recebendo dor sem queixa.

\section{A PROFISSIONALIZAÇÃO DO RUGBYE AS MUDANÇAS NO PERFIL DO HOMEM JOGADOR}

Quando do estabelecimento da RFU, o rugby era desempenhado pelas classes média alta e média, principalmente das escolas e clubes do sul da Inglaterra, e vetado a homens trabalhadores. Em regulamento promulgado em 1880, esse critério de composição das equipes foi abolido (RIAL, 2000).

Assim, o rugby sofreu o que foi descrito por Phillpots (2000, p. 42-43) como uma "democratização" para a qual contribuíram a aprovação da maioria da população à modalidade e a quantidade de jogadores necessários para uma partida na época, 40 homens. Bourdieu (2003) não utiliza o termo democratização para descrever a popularização (ou massificação) do rugby. O autor percebe nesse movimento do esporte uma estratégia de controle político das massas. Antes de considerar o esporte como uma ferramenta para a formação do caráter, as escolas públicas inglesas, que deveriam assumir a tarefa de enquadrar 24 horas por dia, todos os dias da semana, os adolescentes que estavam sob sua responsabilidade, viram ali um meio de ocupar os últimos a um menor custo, pois, durante a prática esportiva, os estudantes seriam facilmente vigiáveis, dedicar-se-iam a uma atividade saudável e descarregariam a sua violência sobre os colegas, em vez de fazê-las sobre as instalações escolares ou os professores.

Resulta, em parte, desse fato, o desenvolvimento da prática esportiva entre os jovens da classe dominante e, também, das classes dominadas. Reconhecendo essa possibilidade de uso do esporte na mobilização, ocupação e controle de jovens, o poder público e outras instituições e agentes - partidos políticos, sindicatos, igrejas e patrões paternalistas - que concorriam para a conquista simbólica desse estrato da população passaram a auxiliar financeiramente a divulgação do esporte e a constituição de associações esportivas. O esporte se torna objeto de luta política (BOURDIEU, 2003).

Preocupado em assegurar um "envolvimento contínuo e total da população operária”, o patronato oferecia a esta, além de hospitais e escolas, estádios e outros estabelecimentos esportivos (BOURDIEU, 2003, p. 194). No norte industrial da Inglaterra, empresários e industriais locais, especialmente nas regiões de Yorkshire e Lancashire, fundaram uma série de clubes de rugby que atraíram as mais diversas 
classes sociais para a prática do esporte, especialmente, a classe trabalhadora (PHILLPOTS, 2000).

Compunham os clubes de rugby homens que não passaram pelo processo de socialização da escola pública e da universidade inglesas e, portanto, não seguiam, exatamente, os mesmos valores (PHILLPOTS, 2000). A divulgação do rugby desde as escolas de elite até as associações esportivas de massa é acompanhada, tanto de uma mudança das funções que os próprios esportistas dão à prática, quanto de uma transformação da própria prática esportiva (BOURDIEU, 2003).

Os novos jogadores se consideravam cavalheiros e compartilhavam de parte dos conceitos tradicionais de masculinidade das equipes do sul, como a dureza e a força (PHILLPOTS, 2000), porém, aqueles homens que conservaram a nostalgia do rugby universitário tinham dificuldade em admitir o gosto pela violência e a "exaltação do sacrifício obscuro e tipicamente plebeu" que caracterizava os novos jogadores de rugby (BOURDIEU, 2003, p. 196).

Além disso, os jogadores oriundos da classe operária tinham, também, concepções diferentes quanto ao aspecto amador do jogo, refutando-o em favor da profissionalização do esporte (PHILLPOTS, 2000) e de suas exigências correlativas, como a racionalização do treinamento e a "maximização da eficácia específica (medida em 'vitórias', 'títulos' ou 'recordes')" (BOURDIEU, 2003, p. 196). Para esses jogadores, os gastos e as perdas de ganhos salariais devido aos compromissos com as equipes eram consideráveis. Então, ressalvando que não se tratava de uma remuneração pela prática do rugby, os clubes do norte expuseram disposição em executar a compensação dos gastos dos jogadores para, assim, mantê-los e garantir a competitividade entre as equipes (ALASALMI, 2014).

Para compreender as razões pelas quais os jogadores da classe operária apresentavam concepções tão distintas daqueles oriundos da elite quanto ao amadorismo e ao fair play, é preciso lembrar que, para os últimos, a carreira esportiva é praticamente excluída do campo de trajetórias profissionais admissíveis para alguém da classe dominante, excetuando os casos do tênis e do golfe, graças aos seus ganhos distintivos. Já para os rapazes das classes dominadas, a carreira esportiva representa uma das "únicas vias de ascensão social", justificando-se com isso uma das poucas possibilidades de mobilidade social (BOURDIEU, 2003, p. 196).

Esse vislumbre de profissionalização do rugby não agradou à elite, que argumentou que o pagamento era contra os verdadeiros interesses do esporte: o lazer, o prazer e a constituição do caráter do homem inglês, marcado pelo cavalheirismo, lealdade e decência. A produção de ganho monetário significaria a comercialização do esporte e redução do jogo a uma mera competição em que a apreciação do jogo e a produção de valores seriam subordinadas aos resultados (SKINNER; STEWART; EDWARDS, 2003).

Bourdieu (2003) corrobora Skinner; Stewart; Edwards (2003) e acrescenta outro fator para a posição contrária da elite ao ingresso de homens trabalhadores nas equipes e à profissionalização do rugby e, consequente, execução de pagamentos aos jogadores. Para o autor, o esporte, como qualquer prática social, é um objeto 
de lutas "entre as frações da classe dominante e também entre as classes sociais" (BOURDIEU, 2003, p. 189) "pela definição do corpo legítimo e dos usos legítimos do corpo" (BOURDIEU, 2003, p. 190). O esporte no século XIX (e ainda nos dias atuais) traz consigo, a ideologia aristocrática que, além de defini-lo "como atividade desinteressada e gratuita", mascarando "a verdade de uma parte crescente das práticas esportivas", também confere a atividades como o tênis e a equitação majoritariamente praticadas pela elite -, "ganhos de distinção" que, sem dúvida, justificam parte de sua procura (BOURDIEU, 2003, p. 190). A profissionalização do rugby permitiria que homens de camadas populares passassem a praticar esse esporte originalmente reservado à elite e, ainda, possibilitaria sua transformação em espetáculo de massa, reduzindo mais ainda seu lucro distintivo.

Até a década de 1880 , o ethos do rugby como esporte amador existia na Grã-Bretanha sob uma forma relativamente vaga e amorfa. Foi só após a ameaça crescente das classes mais baixas praticarem esportes antes exclusivos da elite que se começou a articular e mobilizar a moral amadora. O principal objetivo desse movimento era conservar formas de participação esportiva que a elite considerava ser um direito exclusivo seu (ELIAS; DUNNING, 1985). Sob a égide de que "jogar por dinheiro seria algo menor nesse esporte que preza tanto a nobreza", a elite manteve as classes mais baixas o mais distante possível de seu enclave (RIAL, 2000, p. 245). Skinner; Stewart; Edwards (2003) corroboram essa percepção e acrescentam que o ethos amador do rugby se expressava na riqueza, na independência e na exclusividade da elite inglesa. Este ethos é ameaçado à medida que a popularidade do jogo se amplia e entra em cascata nas classes mais baixas.

As atitudes dos jogadores trabalhadores e da elite eram bastante diferentes. A classe trabalhadora tinha pouca consideração pelo conceito amplo de valores amadores. Pelo contrário, mantinha uma tradição esportiva que enfatizava ganhos, apostas e recompensas materiais. De acordo com essa visão, para que o rugby se tornasse um jogo mais competitivo e de alto nível, as copas e as ligas eram consideradas essenciais, e não o amistoso, que os clubes do sul insistiam em manter (PHILLPOTS, 2000).

A justaposição de clubes de rugby socialmente exclusivos e clubes mais abertos era uma configuração com grande potencial de conflito. Em 1895, em um esforço concentrado em seus mais altos níveis, a RFU criou regulamentos antiprofissionalismo que ampliaram a ruptura entre os clubes do sul e do norte da Inglaterra, e se declarou, estritamente, uma organização amadora (PHILLPOTS, 2000). Até mesmo, as escolas públicas inglesas se mobilizaram em favorecimento ao amadorismo do rugby, acentuando em seu argumento não apenas o prazer como ingrediente essencial do esporte, mas também, "a racionalização educativa do desporto, em particular das equipes, como um instrumento de treino do caráter" (ELIAS; DUNNING, 1985, p. 314).

Como consequência dessas ações, 22 clubes do norte, compostos, entre outros, por homens trabalhadores, retiraram-se da organização e formaram, em 1898, o Northern Rugby Football Union (NRFU), que trazia em seu cerne a marca do profissionalismo, e, em 1922, tornou-se Rugby Football League. Resultado: o jogo 
de rugby dividiu-se em dois formatos diferentes, o Rugby Union (amador) e o Rugby League (profissional), existentes até os dias atuais (ALASALMI, 2014).

Mudanças administrativas estavam ocorrendo, mas para exemplificar o nível de violência a que o rugby ainda atendia, Phillpots (2000) cita dois incidentes, ocorridos na década de 1960, envolvendo jogadores da Inglaterra. Em 1964, Mike Davis estava jogando contra a Nova Zelândia quando deslocou o ombro e, mesmo assim, seguiu em campo naquela partida. Dois anos depois, David Perry também continuou a jogar apesar de lesionar gravemente a cartilagem do joelho após 15 minutos de partida.

Nesse sentido, a partir de 1968, foram permitidas substituições para jogadores lesionados, primeiro em jogos internacionais e, mais tarde, em todas as partidas, o que ajudou a melhorar a imagem do esporte como espetáculo. A noção de que um jogador lesionado deve continuar independentemente da dor para demonstrar seu compromisso com a causa, não mais tinha lugar no esporte moderno. Também não era apropriado sugerir que uma equipe com um ou mais jogadores a menos em campo deveria mostrar seu verdadeiro caráter ao superar essa adversidade com base no argumento de que para alcançar as expectativas dos jogadores e, principalmente, dos expectadores, era - e continua sendo - essencial que a incerteza do resultado fosse mantida durante todo o jogo. Perder um jogador pode levar sua equipe a se esforçar mais e vencer, porém, é mais provável a vitória da equipe com todos jogadores em campo (PHILLPOTS, 2000).

Refletindo sobre as relações de gênero no rugby, Dunning (1985b, p. 399) afirma que a modalidade contribuiu para o desenvolvimento de "expressões simbólicas do machismo". Um exemplo que demarca essa ação no rugby, no século XIX, é a proibição da presença de mulheres em reuniões pós-jogo, com exceção dos casos em que elas ali estivessem "para fazer chá, preparar e servir refeições e para admirar e animar os seus homens" (DUNNING, 1985b, p. 402). Ou seja, a presença das mulheres seria tolerada em reuniões dos jogadores desde que se mantivessem em posição de servidão a estes.

Entre outros fatos, ocorriam naquelas reuniões rituais de iniciação em que os novatos eram obrigados a realizar strip-teases, imitações de comportamentos vistos como de mulheres e homossexuais, sob um viés extremamente desrespeitoso e humilhante a essas categorias, e, ainda, tinham seus órgãos genitais profanados "eventualmente, com graxa de calçado ou vaselina" (DUNNING, 1985b, p. 400). O ritual tinha como objetivo inserir oficialmente o jogador no que era considerado como a vida de um homem de verdade, deixando para trás quaisquer aspectos que burlassem as normas de masculinidades pregadas pela equipe e pela sociedade em geral.

No entanto, apesar de inundado por valores patriarcais, o esporte moderno emergiu como parte de uma mudança civilizadora, da qual um dos aspectos foi a transformação, embora tênue, das relações de gênero. Ao lado do processo de profissionalização do rugby, ocorre uma abertura, pequena a princípio, para a participação indireta das mulheres no ambiente esportivo (DUNNING, 1985b). 
Graças à continuidade do processo de emancipação das mulheres, os clubes britânicos já não possuíam as fronteiras de gênero tão demarcadas quanto de início. As estruturas e ideologias referentes ao ideal de masculinidade daquele período e que fundamentaram o código do rugby (aqui entendido como o conjunto de regras do jogo em si, e, também, de valores e condutas valorizados por seus praticantes e apreciadores) se encontravam fragilizadas. Não se fala ainda em participação das mulheres como praticantes do rugby, mas, em um movimento de dupla face, ao menos o papel de visita cortês Ihes foi concedido, desde que acompanhadas por homens. A abertura dos portões dos clubes às mulheres foi causada, em parte, por contingências financeiras que levaram as equipes a usar os bailes como instrumentos de arrecadação de fundos. No entanto, essa mesma abertura também demonstra que, apesar do domínio masculino na sociedade britânica não ter desaparecido, estava sendo combatido e, em certa medida, corroído (DUNNING, 1985b).

Em 1995, a questão do profissionalismo no rugby aumentou e, em 27 de agosto daquele ano, a International Rugby Football Board (IRFB) - órgão mundial de governo do Rugby, criado em 1886 com fins de resolução de disputas e regularização da modalidade - alterou suas regras para, oficialmente, torná-lo um jogo aberto, ou seja, permitir a profissionalização (PHILLPOTS, 2000).

Desde sua instituição, no século XIX, até os dias atuais, o código do rugby passou por diversas transformações. Porém, Light; Kirk (2000) observaram que, mesmo ao final do século XX, alguns valores permaneciam vivos. Em uma escola de elite australiana, os autores encontraram uma clara estrutura de masculinidades conjecturada através do rugby e centrada na dominação, agressão e na competição implacável.

Tomando a utilização do rugby como modo de educação dos corpos masculinos, Connell (1995), em estudo sobre a historicidade das masculinidades, cita que, também no século $\mathrm{XX}$, a modalidade foi instrumento de propaganda do nacionalismo militarista e de uma modalidade de masculinidade caracterizada pela violência na Nova Zelândia. Em estudo realizado na década de 1990, no Brasil, Rial (2000) destaca que, apesar das mudanças no regulamento, os jogadores amadores de rugby ainda defendem a capacidade de suportar a dor como inerente ao jogo, e, assim, permanecer no campo o maior tempo possível. Essas manifestações físicas são, segundo a autora, apreciadas pelos jogadores e consideradas inerentes à figura do que estes chamavam de macho. A dor é vivenciada com "[...] certa dose de prazer; as cicatrizes são exibidas com orgulho e, não raras vezes, ele [o jogador] e seus parceiros sacrificam-se jogando machucados" (RIAL, 2000, p. 235).

Sobre as reuniões pós-jogo, a autora supracitada refere que, no Brasil, elas são conhecidas como terceiro tempo e, assim como no século XIX, são ocasiões em que os integrantes das equipes se encontram em local reservado para tal e com veto ao acesso de mulheres, para realizarem brincadeiras, trotes de iniciação e confraternizações. Proibida de presenciar o terceiro tempo por sua condição de gênero, Rial (2000) diz tender pensar que nesse momento o "[...] cavalheirismo das interações intersexuais, assim como a agressividade regrada, [...] encontra o seu 
contraponto na manifestação de uma suposta selvageria [...], propriedade de quem é macho" (RIAL, 2000, p. 237).

Situações parecidas aos rituais de iniciação citados por Dunning (1985b) são lembradas por Rial (2000), mas neste caso, elas ocorrem no século XX. Marcados pela dor e por momentos em que os ingressantes eram obrigados a simular situações e performances consideradas femininas, o ritual tem objetivo similar ao de cem anos atrás: marcar a passagem do iniciante para a posição de macho.

Durante o longo - e ainda em curso - processo civilizatório, o rugby adotou e redefiniu o caráter cavalheiresco exigido de seus praticantes. No século $X X$, os jogadores de rugby "fazem questão de se mostrarem cavalheiros nas interações intersexuais, ainda que se mostrem selvagens nas interações privadas da equipe", como nos exemplos citados sobre os rituais de iniciação e o terceiro tempo (RIAL, 2000 , p. 245). Em campo, entre outras ações e atitudes vistas como de um gentleman, o jogador de rugby: respeita seus companheiros e seus adversários, seja na vitória, seja na derrota; não desestimula um ou outro; não comemora a marcação de um ponto de forma teatralizada, como ocorre no futebol, e; não agride a torcida adversária (RIAL, 2000).

Observa-se, assim, a configuração de arranjos de masculinidades alternativos àquele anteriormente dominante e assinalado por atos de violência explícita. Ao lado disso - mas, prudencialmente, evitando-se falar em uma relação de causa-efeito -, é possível verificar distintos usos do rugby como prática corporal esportiva.

Não é objetivo deste ensaio discutir o conceito de habitus proposto por Bourdieu, mas importa citá-lo dado a contribuição do autor para a reflexão sobre essa possibilidade polissêmica de uma modalidade esportiva. Bourdieu (2004) entende o universo de práticas esportivas existentes em dado momento histórico como resultante da relação entre dois espaços: (i) o espaço da oferta de modalidades/ modelos passíveis de serem praticados/consumidos, e (ii) o espaço da procura, inscrita nas disposições (o habitus). A oferta inclui as propriedades técnicas das práticas esportivas, suas possiblidades - e impossibilidades - à expressão de diferentes disposições corporais, e suas propriedades estruturais em relação ao conjunto de outras práticas simultaneamente ofertadas. O espaço da procura é constituído pelas disposições esportivas, que, enquanto dimensão do habitus, são "definidas pelo estado atual da oferta (que contribui para produzir a necessidade, apresentando-lhe a possibilidade efetiva de sua realização) e também pela realização da oferta no estado anterior" (e um conjunto de interpretações sobre ela realizado no passado) (BOURDIEU, 2004, p. 214).

Citando Christian Pociello, Bourdieu (2004, p. 213) refere que "o programa de práticas corporais que a palavra 'rúgbi' designa não é o mesmo - ainda que, em sua definição formal, técnica, tenha permanecido idêntico, com algumas poucas mudanças de regras - nos anos 30, em 1950 e em 1980". Também no decorrer dos séculos XIX e XX pode-se observar diferentes práticas de rugby, cabe dizer, não reduzidas às suas definições técnicas, mas que englobam, também, leituras concorrentes que influenciaram, sobretudo, na redução de atos violentos durante o jogo por imposição de um novo sentido de civilidade. 
O rugby, e o fenômeno esportivo em geral, é marcado em sua objetividade e representações, pelos modos de apropriação social operados por agentes dotados de disposições constituídas, ao mesmo tempo, de forma coletiva e particular, e que orientam a prática (BOURDIEU, 2004). Assim, apesar de propriedades intrínsecas (as regras do jogo, etc.) limitarem os usos sociais que podem ser feitos das práticas esportivas, estas apresentam disponibilidade para uma diversidade de usos e interpretações - inclusive em um mesmo período temporal -, e são marcadas, a cada momento, pelos valores dominantes que lhes são atribuídos.

\section{CONSIDERAÇÕES FINAIS}

O esporte, como fenômeno sociocultural, apresenta constantes transformações de ordens técnica, de exposição e de apropriação pela sociedade. Logo, é necessário considerar as particularidades e o tempo histórico das sociedades que o vivenciam e, consequentemente, transformam-no de acordo com sua própria história, cultura e valores. Sendo assim, o rugby não é um elemento isolado e imune às configurações sociais, históricas e políticas. Em determinados momentos, o conjunto de comportamentos, atitudes, emoções e valores propostos no código do rugby atuou como ferramenta de correção de masculinidades dissonantes do modelo hegemônico.

Por outro lado, há fissuras no código do rugby que estabelecem referências para além das estruturas normativas. Apesar do discurso de força e resistência à dor seguir comum às configurações de masculinidades de homens jogadores de rugby, os modos de expressão dessas manifestações sofreram modificações significativas.

Se, inicialmente, o rugby era uma prática corporal restrita aos homens integrantes da elite inglesa, percebe-se que, ao longo de um processo histórico, essa modalidade foi, também, apropriada por homens da classe trabalhadora; homens com masculinidades, contextos sociais, culturais e econômicos distintos daqueles da elite. O uso do corpo para a prática do rugby alcançou - ou foi alcançado - pelos homens de classes econômicas mais baixas, que, por seu turno, acabam por atribuir outros valores ao esporte.

Mas, o rugby não é o único a sofrer modificações, a ser substantivado de formas distintas; o corpo e as masculinidades também o são. Os embates travados entre os homens integrantes da elite e entre estes e os novos jogadores da classe operária por uma definição única ao rugby demonstram a intenção de controlar o uso dos corpos nesta e naquela classe. Nesse ínterim, também as masculinidades são afetadas, pois a prática do rugby, de início, como vimos, não era restrita aos homens, mas aos homens oriundos da elite. Seus corpos poderiam ser fisicamente semelhantes, mas os usos a eles atribuídos não o eram, e estes também definiam as suas masculinidades.

Também é importante ressaltar as mudanças de ordem técnica ocorridas no rugby. Antes espaço em que os praticantes deveriam demonstrar masculinidade marcada pela apreciação de atos explícitos de violência física, o rugby assumiu, aos poucos (e, de modo dominante, mas não total), a ideia de corpos "civilizados", 
integrando-se ao processo ou projeto civilizatório. Novas regras de funcionamento do jogo e, também, de conduta dos jogadores - como o fair play - foram instituídas com fins de controle das ações de violência.

Feitas essas considerações, é possível o surgimento do seguinte questionamento: a configuração dominante de masculinidade foi modificada pelo esporte, ou, o esporte foi modificado pela atuação de masculinidades alternativas? Apesar de legítimo, esse questionamento, acreditamos, apresenta caráter essencialista, pois, no primeiro caso, o corpo se comportaria como uma tela em branco na qual a cultura pintaria as imagens (representações e sentidos) do ser homem e do ser mulher (CONNELL; PEARSE, 2015); e, no segundo caso, o corpo estaria imerso em uma independência tal do meio que o cerca que lhe seria possibilitado atribuir sentidos e significados ao esporte, e a si mesmo, sem influência de quaisquer fatores e agentes culturais. Ocorre que, como salienta Connell; Pearse (2015, p. 96), corpos podem participar de regimes e práticas disciplinares, como o é o esporte, "não porque são dóceis, mas porque são ativos" e "procuram prazer, experiência e transformação". O corpo não é apenas um produto social, mas produto e agente, ao mesmo tempo.

Encerra-se este trabalho com alguns questionamentos. No século XIX, homens da elite inglesa e, mais tarde, da classe trabalhadora, buscaram no rugby uma forma de reafirmar sua masculinidade, seguindo o padrão normativo da época. E hoje, o que os homens jogadores buscam no rugby? Por que não praticar outra modalidade esportiva? Qual o impacto da presença de mulheres no campo de treino sobre as percepções de masculinidades dos jogadores de rugby e, por conseguinte, sobre as relações de gênero nesse espaço? Problematizar essas questões é importante para compreender o esporte como um espaço mediador do processo de construção de masculinidades e feminilidades, quer reproduzindo concepções tradicionais, quer contribuindo para modificações nas relações de gênero da sociedade contemporânea, mas não determinando os arranjos de gênero de uma sociedade.

\section{REFERÊNCIAS}

ALASALMI, Teija. Problems of translating the laws of Rugby Union from English into Finnish. 2014. 138 f. Dissertação (Mestrado) - Department Of Languages, University Of Jyväskylä, 2014. Disponível em: https://jyx.jyu.fi/dspace/bitstream/handle/123456789/44692/ URN:NBN:fi:jyu-201411193295.pdf?sequence=1. Acesso em: 09 set. 2019.

BETTI, Mauro. Educação física e sociedade: a educação física na escola brasileira. 2. ed. São Paulo: Hucitec, 2009.

BOURDIEU, Pierre. Questões de sociologia. Lisboa: Fim de Século, 2003.

BOURDIEU, Pierre. Coisas ditas. São Paulo: Brasiliense, 2004.

BOURDIEU, Pierre. A dominação masculina. 11. ed. Rio de Janeiro: Bertrand Brasil, 2012. 
BRACHT, Valter. Sociologia crítica do esporte: uma introdução. 3. ed. ljuí: Ed. Unijuí, 2005.

CONNELL, Raewyn. Políticas da masculinidade. Educação e Realidade, v. 20, n. 2, p. 185206, jul./dez. 1995.

CONNELL, Raewyn; PEARSE, Rebecca. Gênero, uma perspectiva global: compreendendo o gênero - da esfera pessoal à política - no mundo contemporâneo. 3. ed. São Paulo: nVersos, 2015.

DUNNING, Eric. As ligações sociais e a violência no esporte. In: ELIAS, Norbert; DUNNING, Eric. A busca da excitação. Lisboa: Difel, 1985a. p. 327-354.

DUNNING, Eric. O desporto como uma área masculina reservada: notas sobre os fundamentos sociais da identidade masculina e as suas transformações. In: ELIAS, Norbert; DUNNING, Eric. A busca da excitação. Lisboa: Difel, 1985b. p. 389-412.

DUNNING, Eric; MAGUIRE, Joseph. As relações entre os sexos no esporte. Revista Estudos Feministas, v. 5, n. 2, p. 1-26, 1997.

ELIAS, Norbert. Introdução. In: ELIAS, Norbert; DUNNING, Eric. A busca da excitação. Lisboa: Difel, 1985a. p. 39-99.

ELIAS, Norbert. A gênese do desporto: um problema sociológico. In: ELIAS, Norbert; DUNNING, Eric. A busca da excitação. Lisboa: Difel, 1985b. p. 187-222.

ELIAS, Norbert; DUNNING, Eric. A dinâmica dos grupos desportivos: uma referência especial ao futebol. In: ELIAS, Norbert; DUNNING, Eric. A busca da excitação. Lisboa: Difel, 1985. p. 279-325.

LIGHT, Richard; KIRK, David. High School Rugby: the body and the reproduction of hegemonic masculinity. Sport, Education and Society, v. 5, n. 2, p. 163-176. 2000.

LOURO, Guacira Lopes. Um corpo estranho: ensaios sobre sexualidade e teoria queer. Belo Horizonte: Autêntica; 2004.

PHILLPOTS, Kyle. The professionalisation of Rugby Union. 2000. 324 f. Tese (Doutorado) - Curso de Filosofia na Política, Department Of Politics And International Studies, University Of Warwick, Coventry, 2000. Disponível em: http://wrap.warwick. ac.uk/4498/1/WRAP THESIS Phillpots 2000.pdf. Acesso em: 09 set. 2019.

RIAL, Carmem Silvia. Rugby e judô: esporte e masculinidade. In: PEDRO, Joana Maria; GROSSI, Miriam Pillar (orgs.). Masculino, feminino, plural. Florianópolis: Mulheres, 2000. p. 229-258.

SKINNER, James; STEWART, Bob; EDWARDS, Allan. The Postmodernisation of Rugby Union in Australia. Football Studies, v. 6, n. 1, p.51-69. 2003. 